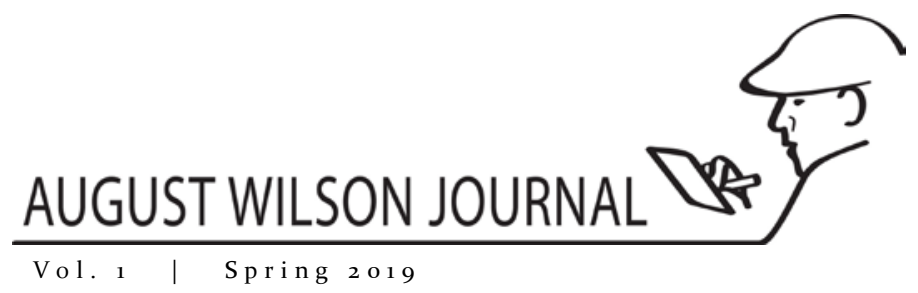

\title{
Welcome to the Stage Review Section of the August Wilson Journal
}

\author{
By Patrick Maley \\ Associate Professor of English, Centenary University
}

The work of August Wilson comes alive most fully in the theater. A poet as much as a playwright, Wilson wrote dialogue with musicality and crafted worlds with texture and nuance. He has given to American theater both a gift and a great burden: his plays teem with potential, but a reaching their greatest heights relies on teams of theater professionals.

August Wilson Journal has a commitment to exploring and engaging with productions of August Wilson's work on stages across the country and the world. We would love to hear from scholars and advanced students of Wilson who are eager to respond to productions and share their views with the world of Wilson scholarship.

Our reviews strive to be short essays that engage with the productions as objects of analyses. Our reviewers are experts speaking to other experts. Reviews might consider the production and its approach within cultural, historical, political and aesthetic contexts, and might

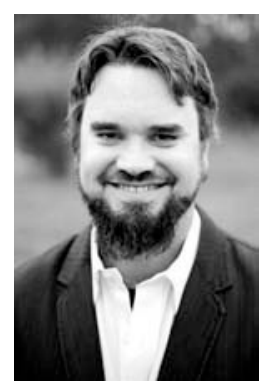

Patrick Maley strive to contextualize the production within the play's performance history and traditions.

In short, performance reviews in August Wilson Journal intend to unite the fields of Wilsonian scholarship and Wilsonian theater with the goal of advancing all of our intellectual and aesthetic engagement with Wilson's work and legacy.

\section{Author Bio}

Dr. Patrick Maley is Association Professor of English at Centenary University where he teaches courses in Shakespeare, drama, classical literature, the history of the English language, and the Bible. 